\title{
Teori Komunikasi Perspektif Indonesia: Gagasan dan Kemungkinan
}

\author{
Abdul Hair \\ Jurusan Ilmu Komunikasi Universitas Brawijaya, Malang, Indonesia \\ e-mail: abdulhair@ub.ac.id
}

\begin{abstract}
This article discusses the possibility of initiating the Indonesian perspective of communication theory, an idea that was derived, while also drawing inspiration, from the Asian perspective of communication theory offered by Kincaid and Dissanayake in the 1980s. The question raised in this article is, is it still relevant to formulate a communication theory based on Indonesian culture, as globalization has increasingly blurred the boundaries between "the local" and "the global"? By using cultural studies and postcolonial theories, as well as literature study methods, the results show that it is possible to initiate communication theory from the Indonesian perspective, although this possibility is still accompanied by a few notes. First and foremost, problematizing the concept of Indonesia itself. Second, conducting dialogue with other scientific disciplines which also criticize the hegemony of Western theories. By adhering to the two notes above, the Indonesian perspective of communication theory is expected to avoid the trap of essentialism and ahistoricism, as seen in various other approaches that also criticize the hegemony of Western theories in communication studies.
\end{abstract}

Keywords: Communication Theory; Postcolonial Theory; Cultural Studies; Asian perspective.

\begin{abstract}
Abstrak
Artikel ini mendiskusikan kemungkinan untuk menggagas teori komunikasi perspektif Indonesia, sebuah gagasan yang diturunkan, sekaligus mengambil inspirasi, dari teori komunikasi perspektif Asia yang ditawarkan Kincaid dan Dissanayake pada dekade 1980-an. Pertanyaan besar yang diajukan dalam artikel ini adalah, masih relevankah untuk merumuskan teori komunikasi yang berbasiskan pada kebudayaan Indonesia, di saat arus globalisasi semakin mengaburkan batas-batas antara "yang lokal" dan "yang global"? Dengan menggunakan teori-teori poskolonial dan cultural studies, serta metode kajian pustaka, didapat hasil bahwa sangat memungkinkan untuk menggagas teori komunikasi perspektif Indonesia, meskipun kemungkinan ini tetap disertai dengan beberapa catatan. Pertama, dan terutama, melakukan problematisasi terhadap konsep Indonesia itu sendiri. Kedua, berdialog dengan disiplin keilmuan lain yang juga melakukan kritik dan gugatan terhadap hegemoni teori-teori Barat. Dengan berpegang pada dua catatan di atas, teori komunikasi perspektif Indonesia diharapkan terhindar dari jebakan esensialisme dan ahistorisisme, seperti yang tampak pada pelbagai pendekatan lain yang juga mengkritik hegemoni teori-teori Barat dalam ilmu komunikasi.
\end{abstract}

Kata kunci: Teori Komunikasi, Teori Poskolonial, Cultural Studies, Perspektif

Pendahuluan

Gugatan terhadap hegemoni

perspektif Barat dalam ilmu sosial

humaniora, termasuk ilmu komunikasi,

bukanlah hal baru. Para sarjana komunikasi

sejak tahun 1980-an, seperti Dissanayake (1988a) dan Kincaid (1987), sudah melakukan gugatan atas hegemoni ini. Tapi di Indonesia, gugatan semacam ini hampir tidak pernah terjadi. Kalaupun ada yang menggugat, seperti yang dilakukan oleh Ratih Puspa (2007), Mario Antonius Birowo 
(2008), dan Turnomo Rahardjo (2013), mayoritas sarjana komunikasi tidak pernah menanggapinya. Adapun gagasan utama yang mereka kemukakan adalah, teori-teori komunikasi Barat tidak serta merta bisa diterapkan di Indonesia, sebab ada perbedaan konteks sosial, budaya, dan politik, antara Indonesia dengan negara-negara Barat tempat teori-teori tersebut lahir. Puspa (2007) misalnya, mengkritik penggunaan teori-teori public relations $(\mathrm{PR})$ Barat di Indonesia, yang acap kali tidak kompatibel dengan kultur Indonesia, tetapi tetap dipaksakan untuk digunakan. Birowo (2008), yang banyak terinspirasi dari Dissanayake (1988a), menawarkan gagasan komunikasi Perspektif Asia untuk tujuan pembangunan. Indonesia adalah negara berkembang, dan pembangunan adalah hal paling krusial yang harus dilaksanakan pemerintah negara-negara berkembang. Pembangunan akan berhasil jika teori yang digunakan untuk menjalankannya digali dari budaya setempat. Sedangkan Rahardjo (2013), berpedapat bahwa problem-problem komunikasi di Indonesia hanya dapat diselesaikan melalui penggunaan teori yang tepat, yakni teori komunikasi yang digali dari kearifan lokal masyarakat Indonesia.

Di tengah seragamnya arah pendidikan dan riset komunikasi di Indonesia yang cenderung pada kajian-kajian administratif (Adiprasetio, 2016; Haryanto, 2001; Rahardjo, 2012), pemikiran ketiga sarjana ini harus diapresiasi dengan tinggi. Meskipun begitu, ada beberapa catatan yang penulis berikan pada gagasan ketiganya. Pertama, penggunaan istilah "kearifan lokal", terutama pada artikel yang ditulis Rahardjo (2013), sangat bias elit. Kearifan lokal sering dimaknai sebagai nilai-nilai adiluhung yang hidup di suatu masyarakat, yang mana nilainilai adiluhung ini merupakan milik kaum bangsawan. Sedangkan nilai-nilai (budaya) rendahan, yang justru lebih banyak dipraktikkan oleh orang-orang kebanyakan, hampir selalu disingkirkan dalam diskusi akademik. Contoh, dalam mengkaji masyarakat Jawa, para akademikus lebih tertarik mengkaji nasihat-nasihat yang diwariskan secara turun-temurun, ketimbang mengkaji penggunaan misuh (makian) dalam interaksi sehari-hari.

Catatan kedua penulis tujukan khusus untuk artikel yang ditulis Birowo (2008). Menggagas teori komunikasi perspektif Asia untuk kepentingan pembangunan semata, sebenarnya mereduksi arti penting dari komunikasi perspektif Asia itu sendiri. Ada dua alasan yang melatarbelakangi argumen ini. Pertama, inti dari gagasan komunikasi perspektif Asia, sebagaimana yang disampaikan Dissanayake (1988b), adalah bagaimana kita bisa memahami cara berkomunikasi masyarakat Asia secara lebih baik melalui penggunaan teori yang tepat dan kompatibel dengan masyarakat yang ingin diteliti. Kedua, sudah terlalu lama ilmu 
komunikasi di Indonesia terjebak pada rezim pengetahuan "pembangunanisme" Orde Baru (Adiprasetio, 2016). Sebab ilmu komunikasi di masa Orde Baru, dan juga ilmu sosial humaniora lainnya, memang dijadikan sarana untuk mendukung pembangunan yang dicanangkan Soeharto. Artinya, pendapat Birowo yang hendak menjadikan komunikasi perspektif Asia untuk tujuan pembangunan semata, justru tidak akan memperluas wilayah kajian ilmu komunikasi di Indonesia, karena tetap berkutat pada hal yang sama.

Catatan ketiga, sekaligus yang paling penting adalah, konsep "kebudayaan lokal" yang mereka pergunakan masih terjebak pada pemahaman yang esensialis. Maksudnya, kebudayaan dipahami memiliki suatu esensi yang murni, terberi, dan tidak pernah berubah walau diterjang zaman. Pandangan seperti ini sebenarnya sudah lama mendapat penolakan, terutama dari akademisi yang terpengaruh pemikiran posstrukturalis. Sebab kebudayaan apa pun, dan di mana pun itu, niscaya untuk berubah. Apalagi dengan fenomena globalisasi saat ini, termasuk kehadiran internet dan penerbangan yang semakin terjangkau, mengakibatkan kita dapat terhubung dengan kebudayaan dari belahan dunia lain. Jika pegaruh kebudayaan luar semakin tidak terelakkan, penggunaan istilah kebudayaan lokal semakin tidak relevan untuk dipergunakan.

Yang menjadi pertanyaan besarnya, dan ini yang hendak dijawab melalui artikel ini adalah, masih relevankah bagi kita untuk merumuskan teori komunikasi yang berbasiskan pada kebudayaan Indonesia, di saat arus globalisasi semakin mengaburkan batas-batas antara "yang lokal" dan "yang global'?

\section{Metode Penelitian}

Riset ini menggunakan metode kajian pustaka. Data didapatkan melalui penelusuran terhadap pelbagai buku dan artikel jurnal yang membahas persoalan teori komunikasi perspektif Asia dan Indonesia sejak dekade 1980-an sampai 2019. Hanya saja, karena pembahasan mengenai topik ini sangat jarang dilakukan di Indonesia, penulis sangat kesulitan untuk mendapatkan literatur yang terbit dalam sepuluh tahun terakhir. Setelah data berhasil dikumpulkan, data yang telah didapatkan tadi dianalisis menggunakan model interaktif Miles, Huberman, dan Saldana (2014).

Analisis data model interaktif ini meliputi; collecting data, data display, condensation, dan conclusion. Pertama-tama, segala buku dan artikel jurnal terkait komunikasi perspektif Asia dan Indonesia akan dibaca terlebih dahulu. Setelah itu data yang tidak relevan akan disingkirkan, sedangkan data yang relevan akan dianalisis lebih lanjut melalui tahapan kedua: penyajian data. Melalui tahapan ini akan terlihat pola besar dalam merumuskan gagasan dan teori komunikasi untuk konteks yang spesifik, sehingga memungkinkan untuk melakukan tahapan analisis selanjutnya: penarikan 
kesimpulan. Pada tahap inilah interpretasi data dilakukan melalui diskusi dan dialog dengan teori-teori poskolonial dan cultural studies.

\section{Hasil Penelitian dan Pembahasan}

\section{Teori Komunikasi Perspektif Asia: Apa dan Bagaimana?}

Sebelum menjawab rumusan masalah yang diajukan di atas, terlebih dulu perlu kita diskusikan teori komunikasi perspektif Asia yang dijadikan acuan dan rujukan dalam menulis artikel ini.

Sebagai disiplin ilmu yang muncul dan berkembang di Barat, terutama di Amerika Serikat, teori dan literatur yang menjadi rujukan dalam pengajaran maupun penelitian komunikasi juga berasal dari Barat. Sebagai contoh, 71 persen literatur yang digunakan untuk pengajaran teori komunikasi di negara-negara Asia Tenggara berasal dari Barat. Di Asia Selatan lebih tinggi lagi, terdapat 78 persen bahan ajar teori komunikasi berasal dari Barat (Dissanayake, 1988b). Fakta ini bisa kita jadikan pijakan untuk mengembangkan kajian teori komunikasi dengan menggunakan perspektif Asia atau "nonBarat".

Ada dua alasan mengapa perspektif Asia perlu dikembangkan dalam kajian teori komunikasi. Pertama, untuk memperluas wacana teori komunikasi, serta mendorong akademisi untuk mengonseptualisasikan perilaku berkomunikasi secara lebih baik. Kedua, teori komunikasi berhubungan erat dengan penelitian komunikasi (Dissanayake, 1988b). Sebab, teori akan membimbing penelitian, dan penelitian akan mendefinisikan sebuah teori. Maka diperlukan teori-teori yang kompatibel dengan konteks sosial, budaya, dan politik di masyarakat yang diteliti, agar hasil penelitian menjadi lebih komprehensif. Teori-teori yang kompatibel bisa diperoleh jika akademisi komunikasi mampu mengonseptualisasikan teori yang digali dari konteks setempat.

Berdasarkan penjelasan di atas, muncullah apa yang disebut teori komunikasi perspektif Asia. Yakni sebuah meta-teori atau mazhab pemikiran dalam kajian komunikasi yang berisi sumber daya, postulat, dan konsep yang berakar dari ragam tradisi masyarakat Asia (Miike, 2002). Definisi ini memiliki tiga implikasi penting. Pertama, teori komunikasi perspektif Asia tidak mengacu pada suatu "kesatuan pengetahuan" (body of knowledge), baik teoritis maupun empiris, tentang sistem berkomunikasi masyarakat Asia. Kedua, teori komunikasi perspektif Asia mencakup pelbagai perbedaan khazanah Asia dan tidak bermaksud untuk menguatkan konsep monolitik di Asia. Ketiga, teori komunikasi perspektif Asia berusaha keras untuk melengkapi, bukan menolak, teori komunikasi Barat (Miike, 2002).

Secara umum ada lima aspek yang bisa dieksplorasi untuk merumuskan teori komunikasi perspektif Asia (Dissanayake, 2009b). Pertama, memeriksa pelbagai teks klasik, yang berisi konsep-konsep komunikasi. Kedua, mengeksplorasi pelbagai tradisi klasik serta praktek-praktek budaya yang ada dimasa 
sekarang. Ketiga, memeriksa pelbagai ritual, upacara, dan pertunjukan (seperti drama rakyat, tarian rakyat, dan seremonial), yang diwariskan dari generasi ke generasi. Keempat, mengeksplorasi perilaku berkomunikasi seharihari. Kelima, memeriksa aspek kebahasaan yang ditekankan oleh pelbagai tradisi agama dan intelektual di Asia. Banyak penelitian yang telah dihasilkan dengan menggunakan lima pendekatan di atas. Di antaranya, penelitian yang dilakukan Yum (1987) mengenai pentingnya uye-ri untuk memahami komunikasi interpersonal orang-orang Korea.

Meskipun sama-sama menggugat dominasi perspektif Barat, dalam perkembangannya, teoritisi utama komunikasi perspektif Asia seperti Wimal Dissanayake, Yoshitaka Miike, Guo-Ming Chen, Eddie C.Y. Kuo, Min-Sun Kim, dan Shelton Gunaratne, justru memiliki pandangan yang berbeda, beragam, dan dalam beberapa hal saling bertolak-belakang. Perdebatan terbuka atas hal ini setidaknya sudah berlangsung tujuh kali di lima jurnal yang berbeda, yakni Asian Journal of Communication, Intercultural Communication Studies, China media Research, Communication Monograph, dan Communication Theory (G. M. Chen, 2002; G. M. Chen \& Miike, 2003; Craig, 2007; Goonasakera \& Kuo, 2000; Miike \& Chen, 2007; Waisbord \& Mellado, 2014; Wang, 2009). Mayoritas akademikus yang menyumbangkan gagasan pada perdebatan tersebut adalah anggota Asian Media Information and Communication Centre (AMIC), sebuah asosiasi sarjana komunikasi yang, salah satu agendanya, mengkampanyekan gagasan komunikasi perspektif Asia. Ini berarti, gagasan komunikasi perspektif Asia bukanlah sebuah meta-teori yang padu dan monolitik. Melainkan sebuah payung besar yang berisi banyak gagasan, dan antara gagasan yang satu dengan yang lain boleh jadi saling bertolak belakang.

Dalam melakukan gugatan terhadap perspektif Barat, secara umum ada empat pandangan yang bisa kita temui. Pertama, melakukan provinsialisasi teori. Pandangan ini berangkat dari asumsi bahwa kondisi sosial dan budaya yang khas seharusnya menghasilkan teori yang juga khas, sehingga dikonstruksilah teori yang secara ekslusif berlaku di Asia. Dalam amatan penulis, pandangan inilah yang paling banyak digunakan para sarjana komunikasi, termasuk Puspa (2007), Birowo (2008), dan Rahardjo (2013), dalam mengonstruksi teori komunikasi perspektif Asia. Kedua, melakukan modifikasi dan adaptasi teori Barat terhadap konteks sosial dan budaya yang diteliti. Gagasan Alwi Dahlan, yang dikenal sebagai bapak ilmu komunikasi Indonesia, mengenai "membumikan ilmu komunikasi” termasuk dalam kategori ini.

Ketiga, menerima kekhasaan konteks sosial dan budaya, namun tetapi mengakui universalitas teori. Contoh paling terkenal dari kategori ini datang dari Miike (2007), Chen (2009), Gunaratne (2009), Kim (2009), serta Kuo dan Chew (2009). Miike (2007: 277) misalnya, menyatakan bahwa komunikasi perspektif Asia harus melampaui pemikiran dualistik yang 
memisahkan antara teori yang spesifik dengan universalitas teori. Tugas dari sarjana komunikasi adalah menghasilkan teori yang "beresonansi penuh" dengan konteks lokal, dan disaat yang bersamaan, mengusulkan kemungkinan implikasi globalnya. Maksudnya, teori komunikasi harus kompatibel dengan konteks lokal, dan sebisa mungkin dapat diterapkan dalam konteks global yang lebih luas. Senada dengan Miike, Chen (2009) berargumen bahwa sarjana komunikasi Asia harus melampaui perdebatan yang mendikotomikan antara budaya-spesifik (konteks lokal) dengan budayaumum (budaya universal). Untuk bisa melampaui dikotomi ini, Chen menggunakan konsep theorics. Yakni sebuah konsep yang dia pinjam dari Naroll (1971), untuk menjelaskan bahwa setiap budaya pada dasarnya bersifat universal tetapi dengan "aksen" lokal yang berbeda-beda. Contoh, konsep citra diri, bagaimana setiap orang selalu berusaha menjaga citra, prestise, atau posisi sosialnya ketika berkomunikasi dengan orang lain. Ting-Toomey (1988) kemudian merumuskan teori face negotiation untuk menjelaskan fenomena ini. Citra diri, bagi Chen, bersifat universal tetapi dengan variasi bentuk yang berbeda-beda di setiap tempat. Masyarakat China, misalnya, mengenal konsep miantze, atau masyarakat Sulawesi Selatan dengan konsep siri'nya, yang merupakan versi lokal dari teori face negotiation.

Pandangan terakhir dalam menggugat perspektif Barat adalah dengan melakukan dialog kritis terhadap teori-teori poskolonialisme, posstrukturalisme, posmodernisme, dan cultural studies, sebagaimana yang digagas oleh Dissanayake (2006, 2009a, 2009b, 2014) serta Raka dan Radha (2002). Poskolonialisme secara sederhana bisa dipahami sebagai teori yang menggugat dominasi dan hegemoni epistemologi Barat, yang merupakan dampak dari kolonialisme, sebagai cara pandang universal dan tunggal dalam melihat dunia dan seisinya. Teoritikus utama poskolonialme, seperti Edward Said, Gayatri Spivak, dan Homi Bhabha, sangat terpengaruh dengan teori-teori posstrukturalis, yang notabene teori Barat juga. Meskipun berasal dari Barat, teori-teori possrukturalis, bersama posmodernisme dan cultural studies, justru menggugat dominasi wacana Barat itu sendiri, termasuk pelbagai macam dominasi wacana lain. Oleh karena itu, teori-teori tersebut juga dimasukkan dalam kategori ini.

Yang juga perlu digaris bawahi, tidak semua sarjana komunikasi Asia setuju dengan teori komunikasi perspektif Asia, sebagaimana tidak semua sarjana Barat menolak gagasan ini. Salah satu sarjana komunikasi Asia yang menolak gagasan ini adalah Georgette Wang dan Vincent Shen. Mereka berpendapat bahwa gagasan teori komunikasi perspektif Asia sejak awal sudah memiliki kontradiksi internal, yakni kontradiksi antara "konsep teori" dengan "bangunan teori yang spesifik untuk wilayah geografis tertentu”. Salah satu sifat teori adalah bersifat universal, sebab syarat sebuah gagasan dapat disebut sebagai teori jika dia memiliki 
kemampuan generalisasi. Maka dari itu, teori yang hanya relevan untuk konteks sosial, budaya, atau orang-orang tertentu saja, tidak bisa disebut sebagai teori, dan lebih tepat disebut sebagai hipotesis yang longgar (loose hypothesis) (Wang \& Shen, 2000). Sedangkan Denis McQuail, salah satu sarjana komunikasi Barat paling disegani di dunia, justru setuju dengan gagasan komunikasi perspektif Asia. Menurut dia, teori-teori media yang ada saat ini jelas mengandung bias budaya, sebab etnosentrisme Barat turut membentuk teori-teori tersebut sejak awal. Maka dari itu dibutuhkan keragaman teori media untuk mengatasi meningkatnya interaksi antara teknologi komunikasi dengan penggunaannya pada konteks sosial dan budaya yang berbeda, termasuk interaksi media dengan masyarakat di Asia (McQuail, 2000).

Lalu bagaimana dengan teori komunikasi perspektif Indonesia? Sebelum mendiskusikannya lebih jauh, perlu kita problematisasikan terlebih dulu istilah dan gagasan Indonesia, termasuk gagasan turunannya seperti bangsa Indonesia, budaya Indonesia, dan Bahasa Indonesia.

\section{Memproblematisasikan Indonesia}

Sejak dekade 1980-an sampai saat ini tidak ada satupun tulisan dengan topik teori komunikasi perspektif Asia, dengan pengecualian artikel Wang dan Shen (2000), yang isinya memproblematisasikan konsep Asia itu sendiri. Padahal, hal ini sangat penting untuk dibahas mengingat konsep "Asia” menjadi kata kunci utama dalam merumuskan teori untuk konteks yang spesifik. Asia, dengan segala pemahaman tentangnya, cenderung diterima begitu saja sebagai suatu yang terberi, seolaholah Asia yang kita kenal saat ini sudah eksis sejak zaman dulu kala. Selain itu Asia selalu ditempatkan sebagai sesuatu yang niscaya berseberangan dengan Barat, seolah-olah Asia dan Barat merupakan dua dunia yang terpisah dan tidak pernah ada hubungan dialogis antar keduanya. Karena hal inilah maka Dissanayake (2009b) menyebut banyak teori-teori komunikasi perspektif Asia yang terjebak pada ahistorisisme dan esensialisme, termasuk teori-teori yang dia gagas pada dekade 1980-an, sebab teori-teori tersebut dibangun tanpa terlebih dulu mempertanyakan asumsi-asumsi yang terlanjur diterima begitu saja mengenai Asia.

Untuk masalah ini, proyek komunikasi perspektif Asia harus belajar pada "disiplin keilmuan" sosial humaniora yang lain. Salah satunya adalah Inter-Asia Cultural Studies, yakni sebuah proyek intelektual yang bertujuan mendialogkan cultural studies dengan konteks masyarakat Asia. Berbeda dengan proyek komunikasi perspektif Asia yang cenderung menerima begitu saja konsep Asia, hal pertama yang dilakukan oleh para akademikus yang tergabung dalam proyek Inter-Asia Cultural Studies adalah memperoblematisasikan istilah Asia dan "Timur" itu sendiri. Hal ini bisa dilihat dalam pengantar Chen (1998) untuk buku Trajectories yang merupakan terbitan pertama dari proyek Inter-Asia Cultural Studies. Atau 
artikel Sun (2000a, 2000b) dengan judul "How Does Asia Mean?” yang terbit di edisi perdana jurnal Inter-Asia Cultural Studies. Bagi Chen (1998), apa yang disebut sebagai "Barat" dan "Timur", atau "Utara" dan "Selatan", tidak lain merupakan kategori ciptaan kolonial dan imajinasi imperialisme belaka. Sedangkan Sun (2000a, 2000b) menjabarkan dua arus utama intelektual Asia, khususnya Jepang, dalam merumuskan Asianisme. Yakni, pertama, berasal dari Fukuzawa Yukichi, yang berpendapat bahwa Jepang harus meninggalkan "sekutu tak terkendalinya" di Asia untuk segera bergabung dengan jajaran kekuatan Eropa dan Amerika. Sedangkan arus kedua berasal dari Okakura Tenshin, yang berpendapat bahwa Asia itu satu, sebab kesamaan peradaban Asia dalam mewujudkan nilai "cinta" dan "keindahan" tidak dapat ditawarkan dan digantikan oleh peradaban Eropa. Meskipun memproblematisasikan Asia dengan cara yang berbeda, baik Chen maupun Sun sepakat bahwa gagasan tentang Asia tidak muncul sejak dulu kala, dalam artian bersifat esensialis. Melainkan hasil konstruksi sosial dan produk peradaban modern yang baru muncul belakangan sebagai respons atas hegemoni Barat.

Agar tidak terjebak pada ahistorisisme dan esensialisme seperti proyek komunikasi perspektif Asia, maka sebelum menggagas teori komunikasi perspektif Indonesia, terlebih dulu perlu kita problematisasikan konsep Indonesia itu sendiri. Problematisasi ini juga mencakup apa itu bangsa Indonesia, budaya Indonesia, dan bahasa Indonesia. Sebenarnya sudah ada beberapa akademikus yang juga memproblematisasikan hal yang sama. Beberapa di antaranya adalah Ariel Heryanto (1989) dan Daniel Dhakidae (2008). Seperti mereka, penulis juga akan menggunakan teori Benedict Anderson mengenai komunitas-komunitas terbayang sebagai acuan utama dalam membahas persoalan ini.

Bagi Anderson (1991), bangsa adalah komunitas politis dan dibayangkan sebagai sesuatu yang bersifat terbatas secara inheren sekaligus berkedaulatan. Bangsa bersifat terbayangkan karena para anggota bangsa terkecil sekalipun tidak bakal tahu dan takkan kenal sebagian besar anggota lain, tidak akan bertatap muka dengan mereka itu, bahkan mungkin tidak pernah pula mendengar tentang mereka. Namun toh di benak setiap orang yang menjadi anggota bangsa itu hidup sebuah bayangan dan keyakinan tentang kebersamaan mereka. Bangsa dibayangkan sebagai komunitas yang mana anggota komunitas itu rela, tidak saja melenyapkan nyawa orang lain tapi juga, mengorbankan nyawa sendiri demi suatu rasa persaudaraan dan kebersamaan. Yang menjadi pertanyaan besarnya, dari mana bayangan dan keyakinan seperti itu muncul? Jawaban yang Anderson tawarkan adalah: kapitalisme cetak.

Dalam diskursus dominan mengenai Indonesia, dan ini yang hendak kita gugat, bangsa Indonesia sudah lahir sejak zaman kerajaan Majapahit, bahkan ada yang meyakini sejak zaman Sriwijaya. Artinya konsepsi tentang Indonesia sebagai sebuah bangsa sudah hadir, 
paling telat, sejak abad ke-14. Walaupun, perlu untuk digaris bawahi, konsepsi tentang Indonesia ini hadir dengan penyebutan yang berbeda, yakni Nusantara. Wilayah kekuasaan Majapahit, yang diyakini membentang dari Sumatera sampai Papua, itulah yang dikemudian hari menjelma menjadi wilayah Indonesia. Dalam menggugat diskursus dominan ini, Dhakidae (2008) melontarkan sebuah pertanyaan retoris: "kalau memang ada 'nasionalisme' zaman Majapahit mengapa kekuatan Hindu-Budha tidak memberikan perlawanan keras ketika Islam mempersiapkan jalan menuju penguasaan Nusantara di tepi kehancuran Majapahit?"

Sesungguhnya imajinasi tentang sebuah bangsa bernama Indonesia muncul sebagai respons atas kolonialisme Belanda. Apa yang dibayangkan sebagai wilayah Indonesia pun tidak merujuk pada warisan wilayah Majapahit atau Sriwijaya, melainkan wilayah HindiaBelanda yang notabene di bawah kekuasaan pemerintah kolonial. Sudah banyak kajian yang menggugat kebesaran wilayah yang dikuasai Majapahit. Beberapa diantaranya datang dari Taylor (2003) dan Hasan Djafar. Bagi Djafar, sebagaimana yang diwartakan liputan6.com (2016), Majapahit tidak pernah menguasai seluruh wilayah yang bernama Nusantara, sebab yang dikuasainya hanya mencakup Jawa Timur dan Jawa Tengah saja. Secara etimologi, menurut Djafar, Nusantara berasal dari kata "nusa" yang berarti pulau-pulau atau daerah, serta "antara" yang berarti "yang lain". Dengan demikian, Nusantara bisa diterjemahkan sebagai "daerah- daerah yang lain", yang tentu saja bukan wilayah kekuasaan Majapahit.

Imajinasi tentang wilayah Indonesia yang telah hadir sejak Majapahit, bahkan Sriwijaya, baru hadir belakangan ketika nasionalisme sudah mulai muncul. Para founding fathers menggali sejarah dari masa lalu sebagai basis legitimasi untuk membangun bangsa dan perlawanan terhadap pemerintah kolonial. Menariknya, pengetahuan para founding fathers mengenai Majapahit dan Sriwijaya sebagai kerajaan besar justru datang dari peneliti Eropa, bukan dari kalangan mereka sendiri. Sumber utama informasi tentang majapahit, yakni kitab Desawarnana (atau yang lebih dikenal sebagai Kakawin Negarakertagama), sudah lama hilang di pulau Jawa semenjak kerajaan Islam menguasai wilayah itu. Salinan kitab itu kemudian ditemukan pemerintah kolonial di Bali ketika mereka berhasil menguasai daerah itu pada 1894. Pemerintah kolonial kemudian menerjemahkan kitab itu ke Bahasa Belanda pada 1916, dan melakukan interpretasi bahwa Majapahit dulunya merupakan kerajaan yang besar. Interpretasi inilah yang digunakan Yamin, dan kemudian diyakini sebagian besar masyarakat Indonesia, sebagai sumber inspirasi untuk kampanye-kampanyenya tentang kemerdakaan, dan mendirikan negara baru sebagai suksesor Majapahit (Taylor, 2003).

Cerita tentang Sriwijaya lebih menarik lagi. Tidak pernah ada seorangpun di wilayah Sumatera, juga di daerah mana pun di HindiaBelanda, yang pernah mendengar atau 
mengetahui tentang Sriwijaya. Kerajaan ini baru diketahui keberadaannya setelah seorang sarjana Prancis bernama Coedès pada 1920-an mempublikasikan hasil penelitiannya tentang sebuah kerajaan yang berada di wilayah Sumatera Selatan. Peristiwa ini kemudan diberitakan oleh koran-koran berbahasa Belanda dan Indonesia. Dalam imaji kaum nasionalis, setelah mendengar pemberitaan tersebut tentu saja, Sriwijaya lalu di tempatkan sebagai awal mula kesatuan di wilayah Nusantara, memosisikan kerajaan ini sebagai kerajaan paling penting di wilayah Barat, sebagaimana Majapahit di wilayah Timur (Taylor, 2003).

Nama Indonesia sendiri dicetuskan oleh seorang sarjana Skotlandia bernama James Richardson Logan pada 1850, melalui artikelnya yang berjudul The Ethnology of the Indian Archipelago (Mahfud, 2013). Namun nama ini baru benar-benar populer setelah seorang etnolog Jerman bernama Adolf Bastian menerbitkan sebuah buku yang berjudul Indonesien order die Inseln des Malayischen Archipels, 1884-1894, yang maksudnya adalah kepulauan-kepulauan India atau kepulauan-kepulauan Melayu (Dhakidae, 2008). Nama inipun tidak merujuk pada suatu istilah geopolitik, melainkan geokultural. Saat nama ini semakin populer, para pelajar dan mahasiswa yang kuliah di Belanda, termasuk Hatta, lalu menggunakan nama Indonesia untuk menyebut organisasi paguyuban yang mereka dirikan, yakni Perhimpunan Indonesia. Inilah kali pertama kata Indonesia digunakan sebagai sebuah nama organisasi.
Namun penggunaan kata Indonesia ini pun bukan merupakan sebuah bentuk kesadaran politik atas bangsa dan negara Indonesia, melainkan untuk menyebut perkumpulan dari orang-orang yang berasal dari wilayah geokultural "Indonesia".

Dekade 1920-an adalah puncak dari berkembangnya nasionalisme di HindiaBelanda. Pada dekade ini pula untuk pertama kalinya nama Indonesia digunakan sebagai istilah geopolitik. Hal ini merujuk pada kongres kelima Perserikatan Communis di Hindia (PCH) tahun 1924, yang salah satu keputusannya adalah mengubah nama menjadi Partai Komunis Indonesia (PKI). Nasionalisme menjadi sedemikian berkembang sebab pada dekade inilah kapitalisme cetak mencapai puncaknya di Hindia-Belanda. Nasionalisme berjalan seiring dengan berkembangnya kapitalisme cetak, ditandai dengan diterbitkannya Medan Priyayi yang menjadi pelopor kapitalisme cetak Indonesia, di samping kapitalisme cetak Belanda yang sudah jauh berkembang sebelumnya (Dhakidae, 2008).

Merujuk pada penjelasan Anderson (1991), terbentuknya imajinasi atas sebuah bangsa yang kelak dinamakan Indonesia dimulai dari sekolah-sekolah yang dikelola pemerintah kolonial di Batavia. Para pemuda yang berasal dari berbagai penjuru Hindia-Belanda, dari Sumatera sampai Maluku, lalu belajar bersama di sekolah-sekolah tersebut. Sekolah-sekolah ini sangat terstandarisasi. Mulai dari buku-buku yang digunakan, guru-guru yang tersertifikasi, 
sampai bahan ajar yang dipakai, semuanya menciptakan pengalaman dan imajinasi yang sama antara siswa yang satu dengan siswa yang lain. Karena mempelajari peta-peta koloni, lamakelamaan mereka, yang berasal dari suku, daerah, dan bahasa ibu yang berbeda ini, lantas mengimajinasikan diri mereka sebagai sebuah komunitas besar yang berada di bawah kendali rezim kolonial Belanda. Dampak dari imajinasi ini amat dahsyat. Penduduk Sumatera dengan penduduk Semenanjung Melayu, yang memiliki keterkaitan suku, memahami ucapan masingmasing, menganut agama yang sama, dan hanya dipisahkan oleh sebuah selat, justru merasa satu sama lain sebagai orang asing hanya karena keduanya dikuasai oleh pemerintah kolonial yang berbeda. Bandingkan dengan penduduk Sumatera dengan Maluku, yang antara keduanya tidak memiliki kesamaan bahasa ibu, kesukuan, agama, dan dipisahkan rentang jarak yang teramat jauh, tapi mereka justru saling merasa sebagai sesama “orang Indonesia".

Ketika kapitalisme cetak mulai tumbuh subur di Hindia-Belanda, kaum terpelajar ini kemudian menemukan cara untuk mempropagandakan keresahan dan pengalaman yang mereka alami melalui surat kabar. Tulisantulisan mereka itu kemudian dibaca oleh orang lain dari pelbagai penjuru Hindia-Belanda, hingga membangkitkan imajinasi yang sama sebagai korban penindasan rezim kolonial. Maka terbangunlah sebuah bayangan dan imajinasi dalam pikiran mereka sebagai sebuah komunitas besar, yang disatukan oleh nasib yang sama, yang kelak mereka namai sebagai bangsa Indonesia.

Dalam diskursus dominan tentang Indonesia, bangsa Indonesia dibayangkan memiliki suatu kebudayaan asli bernama budaya Indonesia, yang merupakan warisan zaman kerajaan Hindu, Budha, dan Islam. "Kebudayaan asli” ini terus hidup di Indonesia sejak berabadabad lalu, sebelum diinterupsi oleh rezim kolonial Belanda selama 350 tahun. Itulah sebabnya segala bentuk kebudayaan Barat dianggap sebagai kebudayaan asing. Bagi Hadiz dan Dhakidae (2006), karya-karya Koentjaraningrat, yang dikenal sebagai bapak Antropologi Indonesia, memainkan peran yang sangat besar dalam mendefinisikan apa itu kebudayaan Indonesia. Salah satunya melalui bukunya yang paling terkenal, dan sampai 2015 telah mengalami 21 kali cetak ulang, yakni Kebudayaan, Mentalitas, dan Pembangunan yang terbit pertama kali pada 1974.

Dalam buku itu Koentjaraningrat (2015) mendefinisikan apa itu kebudayaan nasional Indonesia, yang menurutnya adalah produk kesenian yang berasal dari pelbagai daerah di Indonesia, membuat bangga sekaligus memberi identitas pada masyarakatnya, serta memiliki mutu yang tinggi. Atau dengan kata lain, kebudayaan nasional Indonesia adalah produk kesenian adiluhung. Definisi ini, bagi penulis, sangat bermasalah karena dua alasan. Pertama, makna kebudayaan dipersempit menjadi kesenian semata. Kedua, sangat bias elit, sebab kesenian yang dianggap bermutu dan baik 
hanyalah yang berasal dari kalangan bangsawan, sedangkan kesenian yang berasal dari masyarakat kebanyakan dianggap "tidak bermutu" dan "tidak baik". Pendefinisian kebudayaan seperti ini sudah lama mendapat gugatan. Salah satunya berasal dari Raymond Williams, yang mendefinisikan kebudayaan sebagai keseluruhan cari hidup dan apa yang kita alami sehari-hari (Williams, 1960). Definisi ini menggugat pemahaman kebudayaan yang sempit dan elitis, sebab kebudayaan adalah sesuatu yang bisa kita temui dalam kehidupan sehari-hari, tidak hanya kesenian saja, dan dialami oleh seluruh lapisan masyarakat, tidak hanya dari kalangan bangsawan semata. Dengan definisi yang sangat luas ini, maka penggunaan misuh (makian) oleh masyarakat Jawa dalam interaksi sehari-hari, adalah suatu bentuk kebudayaan juga.

Dalam kajian poskolonial, keyakinan mengenai adanya suatu kebudayaan asli sudah lama mendapat penolakan, salah satunya dari Homi Bhabha yang notabene teoritikus utama kajian poskolonial. Menurutnya, salah satu dampak dari bertemunya penjajah dan yang dijajah adalah pertukaran budaya. Maka dari itu percampuran budaya, atau hibriditas, adalah hal yang tidak dapat dihindari. Kebudayaan penjajah memengaruhi kebudayaan yang dijajah, begitupun sebaliknya. Maka usaha untuk kembali kepada suatu "kebudayaan asli", sebagai salah satu bentuk dekolonisasi, adalah hal yang sia-sia belaka dan tidak dapat dipertahankan lagi (Bhabha, 2004).
Ariel Heryanto, salah satu akademikus Kajian Indonesia yang paling disegani, dalam beberapa kesempatan juga menggugat suatu keyakinan akan adanya kebudayaan lokal yang asli, murni, dan kodrati (Heryanto, 2008, 2015). Bagi dia, kebudayaan lokal ini sejak dulu penuh dengan perubahan, saling-silang, dan saling memengaruhi dengan kebudayaan lain dari pelbagai belahan dunia. Oleh karena itu, apa yang saat ini kita kenal sebagai kebudayaan Jawa sebenarnya merupakan contoh asimilasi lintas tradisi semacam itu. Budaya Jawa yang kita kenal saat ini tidak lain merupakan kebudayaan Hindu dan Buddha yang telah bersentuhan dengan kebudayaan setempat. Selain itu, kebudayaan Hindu, Buddha, dan Islam yang selama ini dianggap sebagai kebudayaan asli Indonesia, sebenarnya tidak berbeda dengan kebudayaan Barat karena sama-sama kebudayaan impor. Hindu dan Buddha, kita tahu bersama, berasal dari Asia Selatan, sedangkan Islam berasal dari Timur Tengah.

Di kesempatan lain, Heryanto (1989, 1992) dengan sangat bagus menjelaskan bahwa Bahasa Indonesia tidak lain merupakan proyek ciptaan pemerintah kolonial, dan bukannya suatu produk budaya yang asli Indonesia. Konsepsi kita tentang Bahasa saja, yang merupakan terjemahan dari language, sama sekali tidak khas Indonesia. Istilah Bahasa memang sudah dikenal sejak lama oleh etnis Melayu. Tetapi "Bahasa" dalam pengertian masyarakat Melayu lama dengan Bahasa dalam pengertian modern, memiliki arti dan makna yang sangat berbeda. 
"Bahasa" bagi masyarakat Melayu lama bisa diartikan sebagai tingkah laku yang positif dan baik, sedangkan Bahasa dalam pengertian sekarang adalah sistem kata yang dipergunakan untuk kepentingan komunikasi. Pengertian "Bahasa" menurut masyarakat Melayu lama bisa dikatakan sudah lama hilang, digantikan oleh Bahasa dalam arti language seiring dengan masuknya pengetahuan Eropa dimasa pemerintahan kolonial Belanda. Dengan demikian, masyarakat Melayu dulu, atau masyarakat mana pun di Nusantara, sama sekali tidak memiliki wawasan dan konsepsi tentang Bahasa dalam artian language, termasuk konsepsi turunannya seperti Bahasa Melayu, Bahasa Jawa, Bahasa Sunda, Bahasa Indonesia, Bahasa Inggris, dll. Sebab dalam semesta berpikir masyarakat Melayu lama, tidak ada yang namanya suatu sistem yang mengatur tata cara penggunaan kata, yang antara kata yang satu dengan kata yang lain bisa saling diterjemahkan. Selain itu, tidak dikenal pula gagasan mengenai terpisahnya "kata" dengan "realitas", yang dalam teori lingustik modern dikenal dengan istilah arbitrer, sebab antar keduanya adalah sesuatu yang tidak terpisahkan. "Kata" membentuk "realitas", begitupun sebaliknya. Itulah sebabnya dalam masyarakat Melayu lama, mantra dipahami sebagai sarana untuk menciptakan atau mengadakan suatu realitas.

Bahasa Indonesia sendiri, sebagaimana yang telah disebutkan di atas, adalah ciptaan pemerintah kolonial Belanda lewat suatu panitia kerja yang diketuai oleh Charles Adriaan van
Ophuijsen (Heryanto, 1992). Bahasa Indonesia diciptakan untuk menandingi bacaan-bacaan kaum nasionalis yang menggunakan Bahasa Melayu Rendah. Kalangan nasionalis menggunakan Bahasa Melayu Rendah agar tulisan-tulisan mereka mengenai antikolonalisme dapat dibaca sebanyak mungkin orang, termasuk dari kalangan bawah yang sehari-harinya menggunakan Bahasa ini. Agar bacaan tersebut menjadi tidak terbaca, pemerintah kolonial lalu menciptakan suatu Bahasa baru yang dinamakan Bahasa Indonesia. Bahasa ini adalah adaptasi dan turunan dari Bahasa Melayu Tinggi, yang notabene hanya dipergunakan oleh sebagian kecil masyarakat saja.

Dari pemaparan di atas, yang ingin ditekankan di sini adalah, apa yang kita sebut sebagai Indonesia tidak lain merupakan produk peradaban modern, dan bukannya sesuatu yang sifatnya asali dan sudah ada sejak dulu kala. Konsep Negara-Bangsa yang kita pergunakan saat ini adalah konsep yang diimpor dari Eropa, yang dalam Bahasa Inggris dikenal dengan istilah Nation-State. Nama Indonesia pun adalah ciptaan orang Eropa. Pengetahuan kita tentang Majapahit dan Sriwijaya, dua kerajaan yang oleh para founding fathers diposisikan sebagai cikal bakal Indonesia, juga kita dapatkan dari orang Eropa. Wilayah Indonesia yang membentang dari Sumatera sampai Papua tidak lain merupakan wilayah kekuasaan pemerintah kolonial Belanda, yang notabene Eropa juga. Apa yang kita sebut sebagai kebudayaan 
Indonesia pun sebenarnya merupakan kebudayaan impor. Yakni saling-silang antara kebudayaan Asia Selatan, Timur Tengah, Eropa, dan kebudayaan-kebudayaan lain dari pelbagai penjuru dunia. Bahasa Indonesia pun, yang pada 1928 diproklamirkan sebagai Bahasa persatuan, tidak lain dari proyek ciptaan orang Eropa. Ini berarti, ketika ingin mendefinisikan tentang Indonesia, mustahil bagi kita untuk keluar dari episteme "Barat". Jika memang demikian, lalu apakah semua nilai-nilai "Barat" harus kita terima? Jika tidak, nilai-nilai "Barat" seperti apa yang harus kita tolak?

\section{Berdialog dengan Disiplin Keilmuan Lain}

Menjawab pertanyaan di atas, tentu saja tidak semua nilai-nilai "Barat" bisa kita terima. Paling tidak, ada dua pandangan "Barat" yang harus kita gugat. Pertama, pandangan tentang universalitas teori. Sejak awal, tujuan utama dari proyek komunikasi perspektif Asia adalah menggugat pandangan ini. Mengakui universalitas teori sama saja dengan mengakui bahwa nilai-nilai "Barat" itu bersifat universal, sebab teori-teori tersebut dibangun di atas pondasi nilai-nilai "Barat". Lawan dari universalitas teori adalah provinsialisasi teori, yakni membangun sebuah teori khas yang berlaku eksklusif di suatu tempat. Provinsialisasi teori ini pun harus kita tolak karena dua alasan: mengawetkan pemahaman yang ahistoris dan esensialis karena beranggapan adanya suatu kebudayaan yang asli, murni, dan asali; serta berpotensi untuk jatuh menjadi rasisme yang baru (anti-asing/'Barat"). Komunikasi perspektif Indonesia harus mengakui bahwa kebudayaan Indonesia saat ini adalah kebudayaan yang hibrid. Yakni hasil percampuran dari pelbagai kebudayaan dunia, baik kebudayaan antara sesama masyarakat Asia, maupun kebudayaan "Barat". Tetapi, penting untuk digarisbawahi, bentuk hibriditas antara wilayah yang satu dengan wilayah yang lain itu berbeda-beda. Hal inilah yang membuat kontekstualisasi teori itu menjadi penting.

Kedua, menolak pola pikir kolonial. Yang dimaksud dengan hal ini adalah pola pikir yang merasa diri superior, rasis, dan menindas. Mengakui "Barat" sebagai patokan dan standar atas segala hal, adalah salah satu bentuk pola pikir kolonial. Sayangnya, pola pikir kolonial ini tidak hanya dianut oleh sebagian, untuk tidak menyebut semua, masyarakat "Barat" saja, tetapi masyarakat Indonesia pun banyak yang menganutnya. Bahkan, ada beberapa teoritikus komunikasi perspektif Asia yang masih menganut pola pikir seperti ini. Salah satu bentuknya adalah, mengawetkan mitos bahwa "Timur" dan "Barat" adalah dua dunia yang terpisah, sebab keduanya mempunyai esensi sejati yang tidak pernah berubah dan lekang oleh waktu. Padahal, mitos tersebut adalah ciptaan "Barat", cara "Barat" untuk membedakan dirinya dengan "yang lain" (the others). Jika "Barat" tidak melakukan pembedaan seperti ini, maka kolonialisme tidak akan tercipta, sebab syarat mutlak terjadinya kolonialisme adalah adanya 
pihak yang merasa lebih superior ketimbang pihak lain.

Dari diskusi di atas, kita dapat menjawab rumusan masalah yang diajukan di awal tulisan ini. Yakni memungkinkan bagi kita untuk menggagas dan merumuskan teori komunikasi perspektif Indonesia. Gagasan ini memiliki beberapa tujuan. Pertama, teori komunikasi perspektif Indonesia bukanlah sebuah teori besar untuk menjelaskan perilaku berkomunikasi seluruh masyarakat Indonesia. Pengertian seperti ini harus ditolak, sebab menganggap bahwa Indonesia itu monolitik. Teori komunikasi perspektif Indonesia lebih tepat dimaknai sebagai sebuah meta-teori yang menggugat penggunaan teori-teori "Barat" yang kurang kompatibel dalam menjelaskan perilaku berkomunikasi masyarakat Indonesia. Kedua, teori komunikasi perspektif Indonesia tidak menolak teori "Barat" secara in toto, melainkan menolak anggapan bahwa teori "Barat" bersifat universal, serta menolak pola pikir kolonial yang bercokol dalam teori-teori tersebut. Penjelasan ini memunculkan dua pertanyaan. Pertama, bagaimana cara untuk menggagas suatu teori yang di satu sisi menggugat "Barat", tapi di sisi lain justru menerima "Barat"? Kedua, apakah teori komunikasi perspektif Indonesia hanya sekadar membahas tradisi-tradisi di Indonesia yang mengandung dimensi komunikasi, ataukah teori ini juga bisa digunakan untuk menjelaskan fenomena komunikasi yang terkait dengan penggunan teknologi komunikasi. Atau dengan kata lain, bisakah teori ini digunakan untuk menganalisis fenomena komunikasi kontemporer, dan tidak jatuh menjadi pembahasan nostalgis tentang nilai-nilai "lokal" yang hidup di masa pra-kolonial?

Untuk menjawab pertanyaan pertama, teori komunikasi perspektif Indonesia harus melakukan dialog, sekaligus belajar dan mengambil inspirasi, dengan disiplin keilmuan sosial humaniora lain. Dari penelusuran yang penulis lakukan, Wimal Dissanayake (2006, 2009a, 2009b) adalah satu-satunya teoritikus komunikasi perspektif Asia yang membuka dialog dengan "disiplin" keilmuan lain dalam mengembang teori komunikasi perspektif Asia, salah satunya dengan cultural studies. Cultural studies sendiri merupakan kajian lintas disiplin yang terinspirasi pemikiran posstrukturalis, yang salah satu agendanya adalah menggugat narasi besar, termasuk dominasi wacana Barat. Cultural studies merupakan kajian yang mengakui kekhasan konteks sosial dan budaya di Asia, tapi tidak menolak Barat secara keseluruhan (in toto), melainkan melakukan dialog kritis terhadap Barat. Maka dari itu, untuk melanjutkan gagasan Dissanayake di atas, penulis mengusulkan proyek komunikasi perspektif Asia, juga komunikasi perspektif Indonesia, untuk berdialog dengan proyek Inter-Asia Cultural Studies. Ada beberapa alasan yang melatarbelakangi hal ini.

Pertama, ilmu komunikasi dan cultural studies memang lahir dari rahim yang berbeda, tapi kajian-kajiannya saling bersinggungan satu sama lain. Itulah mengapa cultural studies, bagi 
beberapa kalangan termasuk National Communication Assosiaciation (NCA), dianggap bagian dari ilmu komunikasi. Secara meta-teori, cultural studies menjadi bagian dari ilmu komunikasi melalui dua jalur. Jalur pertama, melalui tujuh tradisi komunikasi yang di gagas Robert T. Craig (1999), khususnya tradisi kritis. Karena cultural studies berparadigma kritis, maka cultural studies termasuk tradisi kritis dalam ilmu komunikasi. Jalur kedua, melalui ritual view yang digagas oleh James W. Carey, yakni pandangan yang menganggap bahwa komunikasi tidak sekadar transmisi pesan tetapi juga persoalan pemaknaan (Carey, 2008). Karena cultural studies berfokus pada negosiasi makna, maka cultural studies termasuk ritual view dalam ilmu komunikasi. Jika cultural studies dianggap sebagai salah satu perspektif dalam ilmu komunikasi, dan Inter-Asia Cultural Studies adalah salah satu gerakan di Asia yang menggugat dominasi wacana Barat, maka semakin relevan bagi proyek komunikasi perspektif Asia untuk melakukan dialog dengan gerakan Inter-Asia Cultural Studies.

Kedua, meskipun Dissanayake mengusulkan agar proyek komunikasi perspektif Asia berdialog dengan cultural studies, tetapi dalam tulisan-tulisannya, Dissanayake tidak pernah menyinggung proyek Inter-Asia Cultural Studies. Padahal mendialogkan komunikasi perspektif Asia dengan Inter-Asia Cultural Studies mempunyai tingkat relevansi yang lebih tinggi karena sama-sama membicarakan kontekstualisasi teori.
Ketiga, sebagaimana yang disinggung Heryanto (2013), proyek Inter-Asia Cultural Studies adalah salah satu contoh yang berhasil bagaimana cultural studies dan kajian wilayah (area studies), khususnya kajian Asia Tenggara (Southeast Asian studies), diintegrasikan. Kajian wilayah, sebagai sebuah disiplin ilmu, lahir dari para orientalis untuk kepentingan kolonialisme. Mereka mempelajari masyarakat setempat untuk mempermudah mereka dalam melakukan penjajahan. Dikemudian hari, hal ini memunculkan banyak gugatan karena pendekatan yang digunakan dalam kajian wilayah sangat bias orientalis. Kemunculan kajian-kajian tentang dekolonisasi dalam kajian wilayah, tentu saja, menjadi tidak terelakkan. Itulah mengapa istilah indonesianis, yang ditujukan untuk peneliti asing yang mengkaji Indonesia, mendapat gugatan karena istilah tersebut bermakna orientalis. Berdasarkan hal di atas, komunikasi perspektif Asia sebenarnya harus berdialog dengan kajian wilayah, khususnya kajian Asia, karena sama-sama membicarakan masyarakat Asia dan menggugat bias teori-teori Barat. Dan salah satu pintu masuk paling mudah untuk berdialog dengan kajian Asia adalah melalui proyek Inter-Asia Cultural Studies.

Hal ini mengantarkan kita pada jawaban untuk pertanyaan kedua. Dengan melakukan dialog kritis terhadap gerakan Inter-Asia Cultural Studies, komunikasi perspektif Indonesia, dengan demikian, tidak jatuh pada pembahasan nostalgis tentang tradisi-tradisi "asli Indonesia" 
yang hidup pada masyarakat pra-kolonial. Selain karena cultural studies menolak adanya suatu kebudayaan yang "asli” dan "murni”, salah satu topik utama dalam cultural studies adalah budaya pop, yang notabene fenomena komunikasi kontemporer. Di Indonesia sendiri, sangat jarang kajian akademis yang membahas persoalan ini. Padahal fenomenanya sangat masif dan bisa dengan mudah kita jumpai disekitar kita. Sinetron Indonesia, sebagai bagian dari budaya pop misalnya, meskipun fenomenanya sudah berlangsung selama lebih dari 30 tahun, tapi sangat jarang kajian serius yang membahas hal ini. Sinetron sangat digemari masyarakat, setiap harinya ada jutaan orang yang menonton tayangan ini. Bagaimana mungkin produk budaya yang disaksikan jutaan orang setiap harinya luput dari amatan mayoritas sarjana komunikasi di Indonesia? Kalaupun ada yang mengkajinya, pembahasannya tidak lebih dari caci maki ketimbang usaha untuk memahami fenomenanya lebih jauh.

Bagi penulis, sinetron bisa menjadi pintu masuk untuk memahami praktik berkomunikasi masyarakat Indonesia. Berbeda dengan film-film Barat yang mengandalkan kekuatan visual, sinetron justru mengandalkan kekuatan komunikasi lisan, sampai-sampai apa yang dipikirkan oleh karakternya harus disampaikan lewat voice over, ketimbang melalui ekspresi tubuh seperti yang jamak kita temu dalam filmfilm Barat. Hampir tidak ada ruang bagi penonton sinetron untuk mendapat informasi semata-mata dari aspek visual saja. Hal ini sesuai dengan ciri masyarakat Indonesia yang dalam keseharian lebih mengandalkan bentuk komunikasi lisan, ketimbang bentuk komunikasi lain seperti komunikasi tertulis yang dominan di Barat. Artinya, sinetron digemari, salah satunya, karena bentuk komunikasinya tidak bertentangan dengan bentuk komunikasi masyarakat kebanyakan. Dengan melakukan dialog terhadap disiplin keilmuan lain, terutama gerakan InterAsia Cultural Studies, teori komunikasi perspektif Indonesia tidak jatuh menjadi pembahasan nostalgis tentang nilai-nilai "murni" dan "adiluhung" yang hidup dimasa pra-kolonial.

\section{Penutup}

Dari pemaparan di atas, dapat ditarik kesimpulan bahwa sangat memungkinkan bagi kita untuk merumuskan teori komunikasi perspektif Indonesia, meskipun kemungkinan ini harus diberi beberapa catatan. Pertama, sebelum merumuskan teori komunikasi perspektif Indonesia, terlebih dulu perlu diproblematisasikan konsep Indonesia itu sendiri. Hal ini penting untuk dilakukan sebab Indonesia menjadi konsep penting dalam merumuskan teori untuk konteks yang spesifik. Kedua, perlu melakukan dialog dengan bidang keilmuan sosial humaniora lain yang juga melakukan kritik dan gugatan terhadap hegemoni perspektif Barat. Tujuannya agar gagasan komunikasi perspektif Indonesia tidak jatuh pada jebakan esensialisme dan ahistorisisme seperti yang dapat ditemukan pada pendekatan lain dalam ilmu komunikasi yang juga mengkritik hegemoni teori Barat. 
Sebenarnya terdapat beberapa hasil kajian di Indonesia yang membawa semangat komunikasi perspektif Asia dan Indonesia, meskipun kajiankajian seperti ini masih jarang ditemukan dan para penulisnya tidak menyebut pendekatan yang mereka gunakan sebagai komunikasi perspektif Asia dan Indonesia. Dua di antaranya dapat ditemukan pada kajian yang dilakukan Lubis (2019) yang membahas konsep-konsep komunikasi antar budaya yang digali dari ajaran Islam, khususnya hadis Nabi, serta riset yang dilakukan Wahid (2020) mengenai kontestasi dan negosiasi makna "kafir" serta penggunannya dalam interaksi sehari-hari.

Gagasan yang dituangkan dalam tulisan ini tentu saja masih sangat mentah, oleh karena itu sangat terbuka bagi sanggahan, kritikan, dan masukan. Penulis berharap artikel ini dapat memantik perdebatan teoritis dalam ilmu komunikasi di Indonesia, yang sampai saat ini sangat sepi dengan perdebatan. Padahal perdebatan adalah hal yang sangat penting bagi perkembangan suatu disiplin keilmuan. Sebab hanya melalui perdebatan lah suatu gagasan atau teori dapat diuji tingkat kematangannya

\section{Daftar Pustaka}

Adiprasetio, J. (2016). Genealogi Pengkajian dan Ilmu Komunikasi di Indonesia. Universitas Gadjah Mada.

Anderson, B. (1991). Imagined Communities: Reflections on the Origin and Spread of Nationalism (2nd ed.). London: Verso.

Bhabha, H. K. (2004). The Location of Culture. New York: Routledge Classics.

Birowo, M. A. (2008). Perspektif Asia dalam Ilmu Komunikasi: Perlukah Perspektif Asia dalam Kajian Ilmu Komunikasi? Retrieved May 7, 2019, from http://antonbirowo.blogspot.com/2008/11/persp ektif-asia-dalam-ilmu-komunikasi.html

Carey, J. W. (2008). A Cultural Approach to Communication. In Communication as Culture (Revised, pp. 1-28). New York: Routledge.

Chen, G. M. (Ed.). (2002). Culture and communication: An East Asian perspective [Special issue]. Intercultural Communication Studies, 11(1).

Chen, G. M. (2009). Beyond the dichotomy of communication studies. Asian Journal of Communication, 19(4), 398-411. https://doi.org/10.1080/01292980903293312

Chen, G. M., \& Miike, Y. (Eds.). (2003). Asian approaches to human communication [Special issue]. Intercultural Communication Studies, 12(4).

Chen, K.-H. (1998). Introduction: The Decolonization Question. In K.-H. Chen (Ed.), Trajectories: Inter-Asia Cultural Studies (1st ed., pp. 1-46). New York: Routledge.

Craig, R. T. (1999). Communication Theory as a Field. Communication Theory, 9(2), 119-161.

Craig, R. T. (Ed.). (2007). Cultural bias in communication theory [Special issue]. Communication Monographs, 74(2).

Dhakidae, D. (2008). Memahami Rasa Kebangsaan dan Menyimak Bangsa Sebagai Komunitaskomunitas Terbayang. In Imagined Communities: Komunitas-komunitas Terbayang (pp. vii-xlvi). Yogyakarta: Insist Press dan Pustaka Pelajar.

Dissanayake, W. (Ed.). (1988a). Communication Theory: The Asian Perspective (1st ed.). Singapore: Asian Mass Communication Research and Information Centre.

Dissanayake, W. (1988b). The Need for Asian Approaches to Communication. In W. Dissanayake (Ed.), Communication Theory: The Asian Perspective (1st ed., pp. 1-19). Singapore: Asian Mass Communication Research \& Information.

Dissanayake, W. (2006). Postcolonial theory and Asian communication theory: Toward a creative dialogue. China Media Research, 2(4), 1-8.

Dissanayake, W. (2009a). The desire to excavate Asian theories of communication: One strand of the history. Journal of Multicultural

Discourses, 4(1), 7-27. https://doi.org/10.1080/17447140802651629

Dissanayake, W. (2009b). The production of Asian theories of communication: Contexts and challenges. Asian Journal of Communication, 19(4), 453-468. https://doi.org/10.1080/01292980903293411

Dissanayake, W. (2014). Asian television dramas and Asian theories of communication. Journal of Multicultural Discourses, 7(2), 191-196. https://doi.org/10.1080/17447143.2012.666246

Goonasakera, A., \& Kuo, E. C. Y. (Eds.). (2000). 
Towards an Asian theory of communication? [Special issue]. Asian Journal of Communication, 10(2).

Gunaratne, S. A. (2009). Emerging global divides in media and communication theory: European universalism versus non-Western reactions. Asian Journal of Communication, 19(4), 366383. https://doi.org/10.1080/01292980903293247

Hadiz, V. R., \& Dhakidae, D. (2006). Kata Pengantar. In V. R. Hadiz \& D. Dhakidae (Eds.), Ilmu Sosial dan Kekuasaan di Indonesia (1st ed., pp. 1-30). Jakarta: Equinox Publishing.

Haryanto, I. (2001). Propaganda, Kuasa, dan Pengetahuan: Genealogi Ilmu Komunikasi di Indonesia, Suatu Penelusuran Awal. Retrieved from https://ashadisiregar.files.wordpress.com/2009/ 03/microsoft-word-igharyanto_geneologi-ilmukom1.pdf

Heryanto, A. (1989). Berjangkitnya Bahasa-Bangsa di Indonesia. Prisma, 1, 3-16.

Heryanto, A. (1992). Pembakuan Bahasa dan Totalitarianisme. Kritis, VII(2), 18-28.

Heryanto, A. (2008). Pop Culture and competing identities. In Popular Culture in Indonesia: Fluid Identities in Post-Authoritarian Politics. https://doi.org/10.4324/9780203895627

Heryanto, A. (2013). The intimacies of cultural studies and area studies: The case of Southeast Asia. International Journal of Cultural Studies, 16(3), 303-316. https://doi.org/10.1177/1367877912474541

Heryanto, A. (2015). Identitas dan Kenikmatan: Politik Budaya Layar Indonesia. Jakarta: KPG (Kepustakaan Populer Gramedia).

Kim, M. S. (2009). Cultural bias in communication science: Challenges of overcoming ethnocentric paradigms in Asia. Asian Journal of Communication, 19(4), 412-421. https://doi.org/10.1080/01292980903293338

Kincaid, D. L. (Ed.). (1987). Communication Theory: Eastern and Western Perspectives (1st ed.). New York: Academic Press. Inc.

Koentjaraningrat. (2015). Kebudayaan, Mentalitas, dan Pembangunan (21st ed.). Jakarta: PT. Gramedia Pustaka Utama.

Kuo, E. C. Y., \& Chew, H. E. (2009). Beyond ethnocentrism in communication theory: Towards a culture-centric approach. Asian Journal of Communication, 19(4), 422-437. https://doi.org/10.1080/01292980903293361

liputan6.com. (2016). Baru Diketahui, Majapahit Tak Pernah Kuasai Nusantara. Retrieved May 22, 2019, from liputan6.com website: https://www.liputan6.com/regional/read/248546 4/baru-diketahui-majapahit-tak-pernah-kuasainusantara

Lubis, S. A. S. (2019). Hadis Rasulullah Seputar Komunikasi Antarbudaya. Jurnal Interaksi:
Jurnal Ilmu Komunikasi, 3(1), 66-80. https://doi.org/10.30596/interaksi.v3i1.2698

Mahfud, M. (2013). KOMUNIKASI INDONESIA (Studi Komunikasi Nusantara Perspektif Integrasi Interkoneksi). Profetik, 6(1), 5-22.

McQuail, D. (2000). Some reflections on the western bias of media theory. Asian Journal of Communication, 10(2), 1-13. https://doi.org/10.1080/01292980009364781

Miike, Y. (2002). Theorizing Culture and Communication in the Asian Context: An Assumption Foundation. Intercultural Communication Studies, XI(1), 1-21.

Miike, Y. (2007). An Asiacentric Reflection on Eurocentric Bias in Communication Theory. Communication Monographs, 74(2), 272-278. https://doi.org/10.1080/03637750701390093

Miike, Y., \& Chen, G. M. (Eds.). (2007). Asian contributions to communication theories [Special issue]. China Media Research, 3(4).

Miles, M. B., Huberman, A. M., \& Saldana, J. (2014). Qualitative Data Analysis: A Methods Sourcebook. California: Sage Publications Ltd.

Naroll, R. (1971). Conceptualizing the problem, as seen by an anthropologist. Chicago.

Puspa, R. (2007). Personal Influence and Power Distance: Acknowledging Local Cultures Influence in Conceptualising Public Relations Pratices in Asian Countries. Jurnal ILMU KOMUNIKASI, 4(1), 95-106. https://doi.org/10.24002/jik.v4i1.232

Rahardjo, T. (2012). Keseragaman atau Keberagaman: Gagasan Alternatif untuk Pendidikan Tinggi Ilmu Komunikasi di Indonesia. In S. Budi (Ed.), Communication Review: Catatan Tentang Pendidikan Komunikasi di Indonesia, Jerman, dan Australia (1st ed., pp. 1-16). Yogyakarta: Program Studi Ilmu Komunikasi Universitas Atma Jaya Yogyakarta.

Rahardjo, T. (2013). Konstruksi Teori Komunikasi Berbasis Kearifan Lokal. Avant Garde, 1(1), 73-85.

Raka, S., \& Radha, S. H. (2002). Postcolonial approaches to communication: Charting the terrain, engaging the intersections. Communication Theory, 12(3), 249.

Sun, G. (2000a). How does Asia mean? (Part I). InterAsia Cultural Studies, 1(2), 13-47. https://doi.org/10.1080/14649370050141186

Sun, G. (2000b). How does Asia mean? (Part II). Inter-Asia Cultural Studies, 1(2), 319-341. https://doi.org/10.1080/14649370050141186

Taylor, J. G. (2003). Indonesia: Peoples and Histories (1st ed.). New Heaven \& London: Yale University Press.

Ting-Toomey, S. (1988). Intercultural conflict styles: A face-negotiation theory. In Y. Y. Kim \& W. Gudykunst (Eds.), Theories in intercultural communication (pp. 213-235). Newbury Park, 
CA: Sage.

Wahid, A. (2020). Persepsi “Kafir" pada Muslim dan Non-Muslim: Konteks, Penggunaan, dan Komunikasi Partisipatif. Tuturlogi: Journal of Southeast Asian Communication, 1(2), 79-92.

Waisbord, S., \& Mellado, C. (Eds.). (2014). Dewesternizing Communication Studies: A Reassessment [Special issue]. Communication Theory, 24(4).

Wang, G. (Ed.). (2009). Asian Communication Research in Ferment - Moving Beyond Eurocentrism [Special issue]. Asian Journal of Communication, 19(4).

Wang, G., \& Shen, V. (2000). East, west, communication, and theory: Searching for the meaning of searching for Asian communication theories. Asian Journal of Communication, 10(2), 14-32. https://doi.org/10.1080/01292980009364782

Williams, R. (1960). Culture and Society, 1780-1950. New York: Anchor Books.

Yum, J.-O. (1987). The Practice of Uye-Ri in Interpersonal Relationships. In D. L. Kincaid (Ed.), Communication Theory: Eastern and Western Perspectives (1st ed., pp. 87-100). New York: Academic Press, INC. 